\title{
Do earthworms impact metal mobility and availability in soil? A review
}

Article

Accepted Version

Sizmur, T. and Hodson, M. E. (2009) Do earthworms impact metal mobility and availability in soil? A review. Environmental Pollution, 157 (7). pp. 1981-1989. ISSN 0269-7491 doi: https://doi.org/10.1016/j.envpol.2009.02.029 Available at https://centaur.reading.ac.uk/4103/

It is advisable to refer to the publisher's version if you intend to cite from the work. See Guidance on citing.

To link to this article DOI: http://dx.doi.org/10.1016/j.envpol.2009.02.029

Publisher: Elsevier

All outputs in CentAUR are protected by Intellectual Property Rights law, including copyright law. Copyright and IPR is retained by the creators or other copyright holders. Terms and conditions for use of this material are defined in the End User Agreement.

\section{www.reading.ac.uk/centaur}

\section{CentAUR}

Central Archive at the University of Reading

Reading's research outputs online 
Why does earthworm mucus decrease metal mobility?

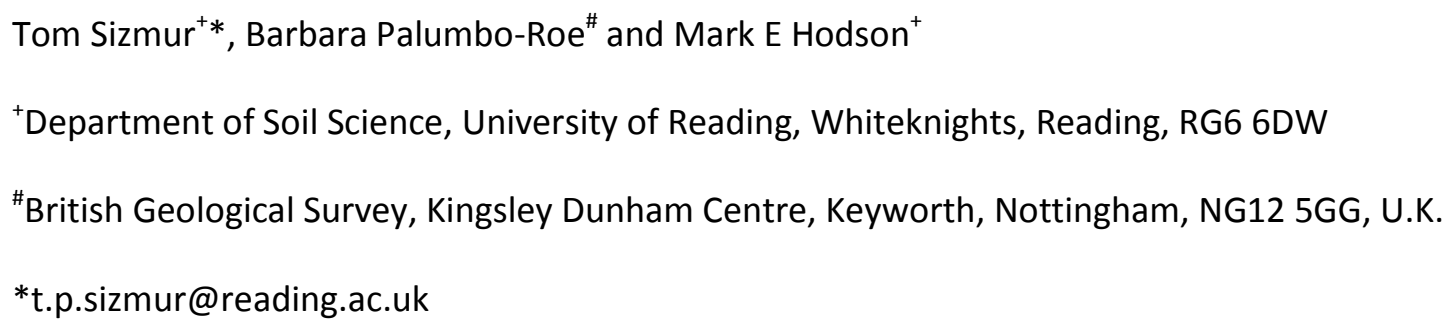

The mining and smelting of metals, application of sewage sludge and other industrial activities have increased the concentrations of metals in many soils throughout the world. It is therefore necessary to assess the risk of these metals causing harm to human health and biota. The methods currently used to do this often involve collecting, drying and storing samples and then carrying out analyses based on chemical extractions abiotically or bioassays on individual organisms, with little consideration for the relationship between soil biota and metal mobility. Soil is not a $2 \mathrm{~mm}$ sieved, abiotic, homogeneous medium and there is therefore no reason to treat it as such during risk assessment of contaminants.

Soil contains a rich diversity of flora and fauna, many of which are known to contribute to the biogeochemical cycling of elements (Beare et al., 1995). Therefore the consideration of soil biota and its influence on the fractionation of metals in contaminated soils is important. Earthworms represent a major constituent of soil fauna. They are known to influence soil properties in a number of ways ranging from improved aeration, drainage and increased microbial activities to increases in organic matter degradation and nutrient availability (Edwards and Bohlen, 1996). It is therefore conceivable that they influence the partitioning, mobility and bioavailability of metals in contaminated soils.

In our first experiments studying the impact of earthworms on metal mobility and availability we incubated individual earthworms (Lumbricus terrestris) in bags of contaminated soil. The earthworms produced burrows and casts and the mobility of most elements increased in the earthworm-inhabited soil. A subsequent experiment in which two earthworms were incubated in the same contaminated soil with the same earthworm-to-soil ratio showed a decrease in the mobility of metals in the earthworm-inhabited soil compared to the earthworm-free soil. This was a puzzling result since one would expect that two earthworms would have the same, or a greater, effect compared to one, rather than the opposite. This observation is in contrast to results of Currie et al., (2005) who suggest the production of earthworm mucus as a mechanism for increased $\mathrm{Pb}$ mobility in treatments with 10 Eisenia fetida earthworms compared to treatments with a single specimen. However, the excreta of L. terrestris and E. fetida are known to be different in composition (Needham, 1957) and may affect the soil chemistry in different ways.

A hypothesis was developed to explain our observation: When earthworms copulate they cover their bodies in a layer of mucus known as a slime tube (Edwards and Bohlen, 1996). It was hypothesised that the mucus produced by the earthworms when they copulate was decreasing the mobility of metals in the soil. In a new experiment earthworm mucus production was stimulated by using sand as an irritant following a method reported by Zhang et al (2009); the mucus was washed off 60 irritated earthworms to give $250 \mathrm{~mL}$ of a dilute, water-based mucus solution. After filtering to remove the sand, the mucus solution was used as leachant in extractions together with deionised water as a control. The mucus solution extracted a lower concentration of $\mathrm{Cu}$ and $\mathrm{Pb}$ than the 
deionised water when used to extract metals from a soil that had been amended with $\mathrm{Cu}, \mathrm{Pb}$ and $\mathrm{Zn}$ salts 15 years ago. There were no significant differences in $\mathrm{pH}$ between each solution. However, there was a greater concentration of organic carbon in the mucus solution compared to the control solution. This is curious since it is known that greater concentrations of dissolved organic carbon in solution increase the mobility of metals (Temminghoff et al., 1997).

We have developed a conceptual model to explain why earthworm mucus decreases metal mobility (Fig 1). It is known that earthworm mucus contains amino acids (Zhang et al 2009), and that amino acids contain both positively (amine) and negatively (carboxylic) charged sites, enabling them to bind to the soil particles and also bind cations from solution. This means that ane site on the soil surface amino acids, or other large organic zwitterions such as proteins, can bind and then complex several metals from solution and thereby reduce the concentration of the metals in the mucus solution and concurrently the mobility of the metals in the soil.

The findings from this study, like many others, throw up more questions than answers. Would earthworm mucus in the soil environment be more dilute or more concentrated than the current study? How long does earthworm mucus persist in the soil environment? Does the same effect happen in every soil type? Why are our results different to those of Currie et al. (2005) - are effects species specific? Experiments are currently being devised to help answer some of these questions and test further hypotheses concerning the impact of earthworms on metal mobility.

There are a few key points that we would like to make from our findings in general. Earthworms are most active when the soil is wet. This is when they copulate the most and produce the most mucus and casts. It is also the time at which there is the greatest risk of metals leaching out of the soil into water courses. The fact that a pair of earthworms have a different impact on metal mobility to a single earthworm indicates that metal biogeochemistry in soil cannot be viewed simply as an abiotic process. There are soil biota that influence the partitioning and mobility of metals in soils which must be considered in risk assessment. Soils should be considered as a single living organism which can bind, uptake, sequester and release metals into the environment.

\section{$\underline{\text { References }}$}

Beare, M., Coleman, D., Crossley, D., Hendrix, P., Odum, E. 1995. A hierarchical approach to evaluating the significance of soil biodiversity to biogeochemical cycling. Plant and Soil 170: 5-22.

Currie, M., Hodson, M.E., Arnold, R.E., Langdon, C.J. 2005. Single versus multiple occupancy-effects on toxicity parameters measured on Eisenia fetida in lead nitrate-treated soil. Environmental toxicology and chemistry 24: 110-116.

Edwards, C.A., Bohlen, P.J. 1996. Biology and ecology of earthworms. London, UK: Chapman and Hall.

Needham, A.E. 1957. Components of Nitrogenous Excreta in the Earthworms Lumbricus Terrestris, L. and Eisenia Foetida (Savigny). Journal of Experimental Biology 34: 425-446.

Temminghoff, E.J.M., Van der Zee, S.E.A.T.M., de Haan, F.A.M. 1997. Copper Mobility in a CopperContaminated Sandy Soil as Affected by $\mathrm{pH}$ and Solid and Dissolved Organic Matter. Environmental Science \& Technology 31: 1109-1115. 
Zhang, S., Hu, F., Li, H., Li, X. 2009. Influence of earthworm mucus and amino acids on tomato seedling growth and cadmium accumulation. Environmental Pollution 157: 2737-2742.

$\mathrm{M}^{2+}$

$\mathrm{M}^{2+}$

$\mathrm{M}^{2+}$

$\mathrm{M}^{2+}$

$\mathrm{M}^{2+}$
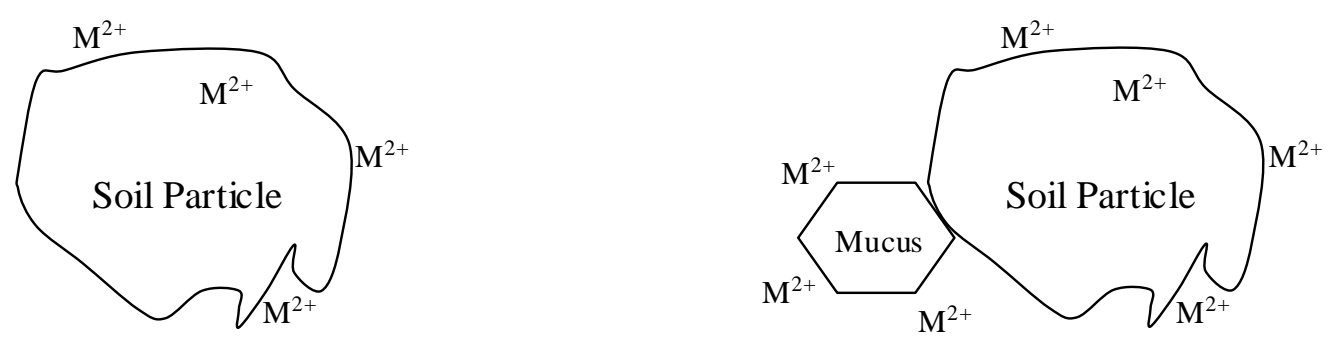

$\mathrm{M}^{2+}$

$\mathrm{M}^{2+}$

Control solution

Mucus solution

Figure 1 A conceptual diagram of metal sorption to a soil particle in a control and earthworm mucus solution. 